\title{
The SEA-change model in Information Literacy: Assessing information literacy development with reflective writing
}

\author{
Research Article
}

\section{Barbara A. Sen* and Pamela McKinney}

University of Sheffield

\begin{abstract}
Reflective writing is a key professional skill, and the University of Sheffield Information School seeks to develop this skill in our students through the use of reflective assessments. Reflection has been used as a means of supporting Information Literacy development in the Higher Education context and recent pedagogical IL frameworks highlight the important role of reflection. This paper presents an analysis of Undergraduate students' reflective writing on one module. The writing is mapped against two models of reflection to understand the nature and depth of the students' reflection and through this understand their Information literacy development, with the overall aim of improving the teaching and learning experience for the future. Key findings are that students did reflect deeply and identified a number of ways in which they felt their IL had developed (e.g. developing a knowledge of specialist sources), ways they could have improved their information literacy practices (e.g. through storing information in a more organised fashion), and ways that we could improve our teaching (e.g. by providing appropriate scaffolding for the activities).
\end{abstract}

Keywords: Information literacy, reflection, teaching and learning

\author{
*Contact: \\ Barbara A. Sen \\ University of Sheffield, UK \\ E-mail: b.a.sen@sheffield.ac.uk
}




\section{Introduction}

The University of Sheffield Information School (or iSchool) is keen to promote a pedagogical focus on reflection, with students required to complete assessments in reflective writing in a number of modules offered to both undergraduate and postgraduate students. This is due to the widely held belief both in the School, and in the University that reflective writing is a key skill we need to develop in our students for both their personal and professional development. Being reflective is just one of the skills expected of a Sheffield graduate that is reinforced across the University. Reflection is an activity that students are increasingly being asked to engage in, for example the Sheffield Graduate Award, which enables students to demonstrate their personal development while they have been a student at the University, requiring students to submit a reflective portfolio. In addition reflective practice supports job search activities such as the creation of CVs, and building a portfolio of examples to use in employer-specific application forms and at interviews. Our work with students on reflective practice is designed to be supportive in developing these reflective skills that will benefit the students in university, and into the workplace.

In this paper we will examine the reflective writing of Undergraduate students who studied the Business Intelligence module in 2010-11 iteration of the module. We will first introduce the module context and activities; outline some models of reflection that we use to frame reflective practice in our teaching and research, briefly review the literature on assessment practices for information literacy, including the use of reflection as a means of assessing information literacy.

\section{Information literacy development in a module context}

The overall objective for this study is to understand the value of reflective writing for students undertaking a reflective exercise in one of their assignments that assesses their information literacy development. The objectives of the study consider:

- What changes in their information literacy capabilities do students demonstrate through their reflective writing?

- How well does the SEA-change model of reflection, developed at Sheffield, enable us (as tutors) to map students' levels reflection, and development of information literacy?

- Is reflective writing an effective means of assessing information literacy development?

In a number of modules students are required to reflect briefly on their experiences of working as a group to satisfy a university requirement that any assessed group project must be accompanied with a short piece of un-assessed reflective writing. In the Business Intelligence module undergraduate students are introduced to reflection through an assessed task requiring them to reflect on their information literacy development. This assessment supports the continuing development of reflective practice in iSchool students.

The Business Intelligence module focuses on theoretical awareness of why organisations need to be aware of the external business environment including competitors, markets and consumers. Students are introduced to these theoretical concepts in the lectures and in practical activities. Through the group coursework they work as business intelligence consultants on behalf of real businesses, carrying out business research for the company. Through this company focused activity the students gain a deeper understanding of the need for information in a business context and its critical application in supporting business planning and decision making.

The students develop their skills in searching for this type of information in what is a fast moving field, with new information products and services being developed all the time. Students develop information agility as the business environment can change quickly from day-to-day. This is one reason why there is such a defined focus on Information Literacy in the module. Equipping the students with developed information literacy skills gives them the ability to react 
to business intelligence situations, and adapt their information behaviour as the need arises. Information Literacy (IL) is, 'knowing when and why you need information, where to find it, and how to evaluate, use and communicate it in an ethical manner.' (CILIP, 2004). It is considered that through becoming information literate, people develop skills and abilities to do with searching for, finding, evaluating and using information that they can apply to any context, thus IL is a so-called 'transferable skill'. The skills these students learn in university are transferable to a wide range of workplace contexts.

In designing the assessment for the module we wanted to make explicit to students that they were developing their IL, but also to find a way of assessing this development. The assessment task to reflect on their IL development together with the accompanying support session was felt to accomplish both these objectives.

\section{Reflective models}

A reflective workshop was designed for the Business Intelligence students which takes place towards the end of the semester. In this session students are introduced to some of the theory behind reflective writing, establishing it as a valid academic and professional activity. Students are then introduced to a particular model of reflection created by Jenny Moon (Moon, 2007) which presents four easy-to-understand levels of reflection.

1. Descriptive writing: Contains little reflection. May tell a story but generally from one point of view.

2. Descriptive writing with some reflection: A descriptive account that signals points for reflection while not actually showing much reflection. What little reflection there is lacks depth.

3. Reflective writing 1: Description, but it is focused, with particular aspects accentuated for reflective comment. Shows some analysis, some self-questioning.

4. Reflective writing 2: Clear evidence of standing back from the event. Shows deep reflection. Self-questioning, and the views and motives of others are also taken into account. Observation that learning has been gained.

In the workshop we made it clear that these levels of reflection are linked to the grades that a student might expect to achieve for their reflective assessment (they are aiming to be deeply reflective - reflective writing 2), and the iSchool assessment rubric makes use of the Moon model in defining the grade boundaries for the assessment of reflective writing. That is when assessing the work we looked for evidence of low level to deep reflection looking for items in Moon's (2007) criteria, for example evidence of self-questioning. Then we selected a grade based on the evidence found in the writing i.e. Moon's level 1 (very low level reflection or) descriptive writing might achieve a grade of up to 49\%, Moon's level 2 (low level reflection or) descriptive writing might achieve a grade of 50-59\%, Moon's reflective writing level 1 might achieve a grade of 60-69\%, Moon's Level 2 (deep) reflective writing might achieve a grade of $70+$.

In a workshop activity, students are asked to write a short reflection using a template provided and then peer review each others' work. They are asked to assess at which level on the Jenny Moon model their reflection falls. This activity we believe helps them engage with the model in a practical way and also places them in the position of the assessor. The students are then encouraged to discuss their reflections with their peer and identify strategies they could both use to deepen the level of reflection. The activity enables the students to practice, and develop their reflective writing skills in a supportive environment and be able to make mistakes in a non-assessed environment, preparing them for the assessed work that they will submit later in the module. A further support document is given to students in this session which contains examples of descriptive and deeply reflective writing. We have developed this approach over a number of years of working with both undergraduate and postgraduate students. The approach was designed to support students as reflective writing is a new experience for students, and even when they have experience, they have rarely has any support or instruction in developing 
their reflective writing skills. As novice reflective practitioners, the students require support, and as they develop their skills, and become more confident, the teachers or mentors apply a progressive "descaffolding" approach to learning support in order to facilitate student autonomy (Lajoie, 2005; Simons \& Klein, 2007).

As a result of the work carried out with students on the Business Intelligence, and other modules a model of reflection, the SEA-change model, has been developed in the Information School designed to aid the understanding of the change that occurs as a results of reflection (Sen \& Ford, 2009).

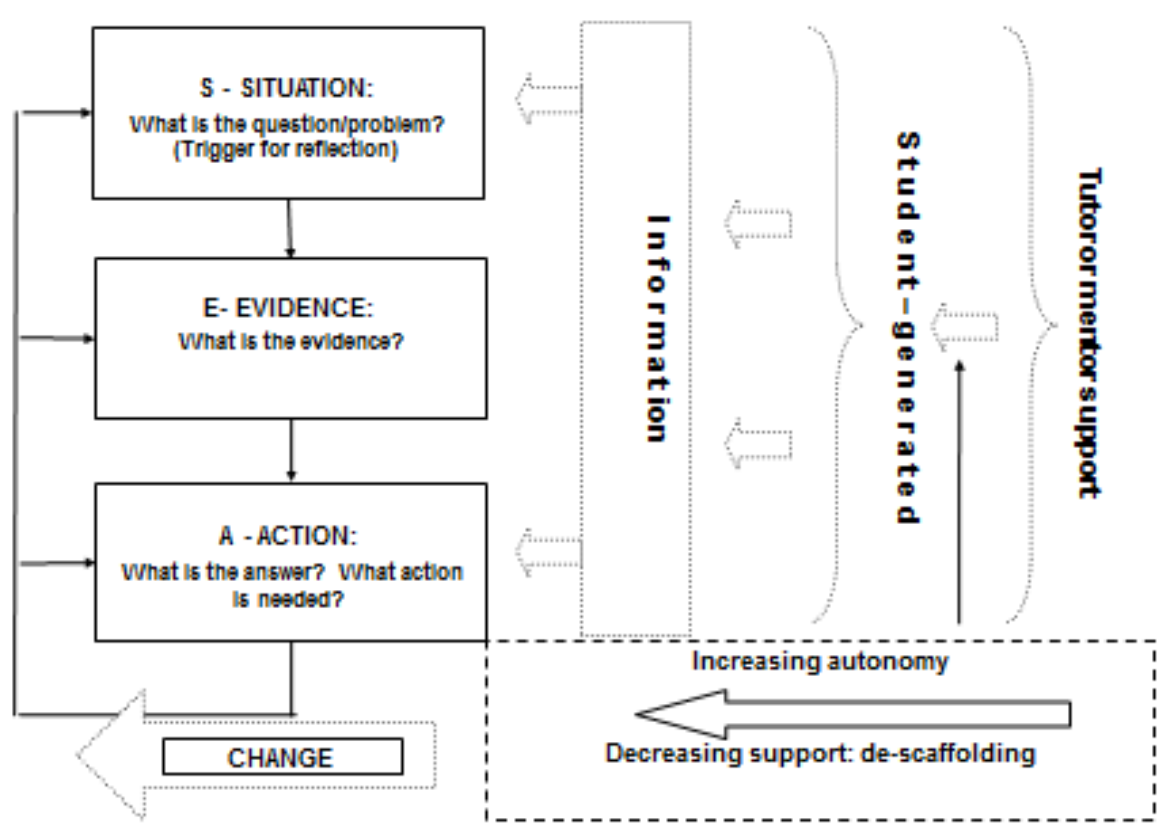

Figure 1. The SEA-change model of reflection adapted from Sen \& Ford (2009).

The model has three core process elements: a consideration of the situation (S); consideration of the evidence used during the practice of reflection (E); and action (A) needed as a result of what has been learnt from the reflective process. What follows the reflection is frequently a need for change, hence the SEA-change model. The model provides a framework for understanding, and for the support and guidance of reflective practice. Those who reflect deeply tend to consider all the points in the process, those who practice low levels of reflection might omit some elements within the process.

Each of the three process elements are broken down further and differences in reflective behaviour are observed between individuals who engage in low level reflection, and those who engage in deep reflection. (Table 1) 


\begin{tabular}{lll}
\hline $\begin{array}{l}\text { SEA-change } \\
\text { process phases }\end{array}$ & Deep reflection process & $\begin{array}{l}\text { Low level reflection some } \\
\text { elements of the process missing }\end{array}$ \\
\hline S- SITUATION & $\begin{array}{l}\text { Trigger and/or catalyst - clearly } \\
\text { defined and understood. }\end{array}$ & $\begin{array}{l}\text { Trigger or catalyst - often not } \\
\text { clearly defined or understood. }\end{array}$ \\
\cline { 2 - 3 } & $\begin{array}{l}\text { Context - Contextual consideration } \\
\text { fully considered. }\end{array}$ & $\begin{array}{l}\text { Context - not always fully } \\
\text { considered. }\end{array}$ \\
\cline { 2 - 3 } & $\begin{array}{l}\text { Critical (analytical or deep) reflection } \\
\text { of multiple perspectives. }\end{array}$ & $\begin{array}{l}\text { Often the reflective focus only on } \\
\text { self and not on multiple } \\
\text { perspectives. }\end{array}$ \\
\hline E- EVIDENCE & $\begin{array}{l}\text { Assimilation of the } \text { evidence from the } \\
\text { past or present. }\end{array}$ & Evidence not fully assimilated. \\
& $\begin{array}{l}\text { Learning process based on } \text { evidence, } \\
\text { new knowledge or understanding } \\
\text { acquired. }\end{array}$ & $\begin{array}{l}\text { Learning at a basic level. Reflective } \\
\text { process often stops here. }\end{array}$ \\
& $\begin{array}{l}\text { Need for action identified based on } \\
\text { above. }\end{array}$ & $\begin{array}{l}\text { Often overlooked OR reflective } \\
\text { process stops here. }\end{array}$ \\
\cline { 2 - 3 } & $\begin{array}{l}\text { What action or change is needed? } \\
\text { Future. }\end{array}$ & $\begin{array}{l}\text { Often overlooked OR reflective } \\
\text { process stops here. }\end{array}$ \\
\cline { 2 - 3 } & $\begin{array}{l}\text { Action or change in behaviour, or the } \\
\text { situation. }\end{array}$ & $\begin{array}{l}\text { Often overlooked OR reflective } \\
\text { process stops here. }\end{array}$ \\
& &
\end{tabular}

Table 1 - The SEA-change model of reflection and the processes of reflection defined (Sen \& Ford, 2009).

In this paper we use the SEA-change model as a framework for understanding and assessing the changes in information literacy capabilities achieved during the course of the students assessed work on the Business Intelligence module.

\section{Literature review}

\section{Assessment of Information Literacy}

This brief literature cannot hope to present a comprehensive view of the approaches to IL assessment in use in the higher education environment worldwide, a much more detailed consideration of these can be found in Walsh (2009). Instead we give an overview of the most popular approaches before looking in greater depth at reflective approaches to IL assessment. In the US often the driver for the design of information literacy learning outcomes are the ACRL Competency Standards for Higher Education, however it is noted that librarians can struggle to design assessments that address these learning outcomes (Mery, Newby \& Peng, 2011). Nevertheless there are many examples in the literature of librarians using the ACRL standards to design questions for institution-specific multiple-choice information literacy competency tests (e.g. Ondrusek, Dent, Bonadie-Joseph \& Williams, 2005; Mulherrin \& Abdul-Hamid, 2010) and project SAILS offers a fee-based, generic multiple-choice IL competency test for US academic libraries, also closely linked to the ACRL standards (Lym, Grossman, Yannotta \& Talih, 2010). Information literacy competency tests are seen to be a way of measuring the extent to which IL skills have been acquired by students, and can be used with students across diverse programmes, particularly when a standard online IL course is used (Mery et al., 2011). The advantage to using standard tests with fixed-choice answers is that they yield quantitative data that can be analysed statistically (Mery et al., 2011), are easy and cheap to administer and offer the ability to compare achievement across a student body (Oakleaf, 2008). However as Oakleaf (2008) points out, fixed choice assessments and the need to have objective and precise measures of performance are based on behaviourist theories of teaching and learning, which are 
not necessarily appropriate for a more constructivist, inquiry-based educational model as they cannot measure higher order thinking skills. Tests such as these also cannot measure the extent to which students can apply their IL skills in real life situations (Sharma, 2007). The ACRL standards themselves have also been criticised for promoting a skills-based conception of information literacy that does not address the complexity of the social use of information. (Jacobs \& Berg, 2011).

An alternative model of assessment is to have performance-based assessments which test students' ability to apply their knowledge and learning, and this type of assessment is grounded in constructivist theories of education which propose that learners construct their own knowledge and which highlight learning through problem solving and critical thinking (Oakleaf, 2008). Sharma (2007) describes the use of a research portfolio that enables students to demonstrate critical thinking and the application of information search and evaluation skills e.g. through the provision of an annotated bibliography. Portfolio assessments are reported to be used in the UK Higher Education context by Sonley, Turner, Myer \& Cotton (2007) who found that they were able to constructively align learning outcomes with this assessment. Annotated bibliographies are widely used as a means of assessing IL competencies (e.g. Wheeler, Vellardita \& Kindschi, 2010; Fallon \& Breen, 2005; Hoffman \& LaBonte, 2012) and are seen to be a way to focus student attention on the information research process that might otherwise be glossed over (Wheeler et al., 2010). A further example of a performance assessment found in the literature is a poster assessment (Kinikin \& Hench, 2012).

Performance assessments, in contrast to IL competency tests, offer the ability to test higher order IL skills, and to offer assessments that are more closely linked to learning activities and that are more contextualized in the subject curriculum (Oakleaf, 2008). However Oakleaf (2008) also presents some potential limitations to performance assessment, namely the increased burden in terms of designing, delivering and marking such assessments and that they are much more situated within a particular educational context meaning that the potential to compare student performance across cohorts is much reduced.

A third model of IL assessment proposed by Oakleaf (2008) is the use of rubrics, or standard scoring schemes, for assessing information literacy, and it is noted that these rubrics can be used to assess a range of performance assessments. Rubrics can be useful in terms of providing feedback to students and can help many assessors apply a standard approach to assessment. However as Hoffman and LaBonte (2012) point out, differences in the application of assessment rubrics can be experienced, although extensive training can address this (Oakleaf, 2008)

\section{Reflection and information literacy assessment}

Many attempts have been made to define and clarify reflection as a term (Bengtsson, 1995; Black \& Plowright, 2010; Moon, 2007). For the purposes of this paper we use the definition by Black and Plowright (2010), as it highlights the relationship between reflection, learning, and practice that is contextually relevant in the environment we work in within Higher Education, that of preparing students for the world of work many of whom become information practitioners. 'Reflection is the process of engaging with learning and/or professional practice that provides an opportunity to critically analyse and evaluate that learning or practice.' (p. 246).

Mezirow (2006) beliefs that when students are provided with the opportunity to reflect on their beliefs, philosophies, and practices, then they are more likely to become life-long learners within their professions. This belief is one that resonates with us from our experiences of supporting students, and receiving their feedback during learning, after learning, and as they become practitioners. Reflection is a way of learning from experiences (Boud, Keogh \& Walker, 1985; Moon, 2004). Critical reflection is a term that is used to describe a process of self- 
reflection and inquiry when a person examines their beliefs and the impacts on their practice (Larrivee, 2000). The terms critical, deep reflection, and analytical reflection are often used interchangeably. Koufogiannakis (2010) describes analytical reflection is as a process which enables professionals to make better judgements and decisions, whilst Moon (2005) uses the term deep reflection when deeper learning is evidenced.

Reflective practice is the use of reflection related to one's own activities to improve future practice; it involves the evaluation of experiences (Moon, 2007). Ghaye (2005) notes the importance of reflection on successes as well as mistakes to inform and improve future practice.

The relationship between reflection and information literacy development has been acknowledged in both the US ACRL competency standards (2001) and the Australia and New Zealand IL framework (ANZIIL, 2004). In the UK the 'New Curriculum for Information Literacy' Secker and Coonan (2011) identifies reflection as an important aspect of the pedagogy for information literacy. Furthermore leading information literacy researchers have identified the role that reflection for IL development can play in supporting constructivist approaches to teaching that encompass aligned assessment (Hepworth \& Walton, 2009; Johnston \& Webber, 2003).

There are various models of reflective practice outlined in the IL literature, for example some IL educators advocate the development of a reflective approach to IL development over the course of a module or programme of study through the use of reflective diaries (Bruce \& Hughes, 2010; Bordonaro \& Richardson, 2004; Diekema et al., 2011; McGuinness \& Brien, 2007). Critical incidents in students' information use can be used to trigger reflections (Bruce \& Hughes, 2010; Gilstrap \& Dupree, 2008).

A reflective approach to IL assessment can be combined with the performance assessment approach outlined above, for example the use of a reflective annotated bibliography, where the reflective element enabled the assessors to better evaluate the students' reasoning process in choosing sources and therefore the extent to which they had applied IL skills in their work. (Hoffman \& LaBonte, 2012).

The benefits of using reflective assessments for information literacy are discussed in the literature. One benefit is that tutors can ascertain the extent to which module learning outcomes have been met (McKinney \& Sen, 2012; Nutefall, 2005). Students' reflections have also demonstrated how they have developed their approaches to the research process, an increased understanding of the library resources available to them and an enhanced understanding of the value of information literacy (Lehlafi, Rushton \& Stretton, 2012).

Jacobs and Berg (2011) recommend that IL educators focus on developing critical consciousness in students about their use of information to support their own learning, and that this enables us to align the pedagogy of IL with both constructivist ideals and also with the ideals espoused by the Alexandria proclamation that place IL at the heart of lifelong learning. The use of reflective assessments aligns closely with these recommendations and ideals.

\section{Methdology}

In the 2010-11 iteration of the business intelligence undergraduate module, a total of 14 students were enrolled. Of these, nine students gave their informed consent to take part in the research, following provision of a detailed participant information sheet as per the University of Sheffield ethical guidelines for research. Eight students were male, one female; two were overseas and seven home students; six students were studying on the BSc Information Management programme, two studied BSc Computer Science and the remaining student studied dual honours BA Accounting and Financial Management and Information Management. Students understood that the reflective writing that they submitted as part of the assessed work 
for the module would form the data for the research project, and they were assured that they would remain anonymous in any subsequent reporting.

The students each submitted a reflective report of approximately 800 words on their individual experiences of searching for business information for their group work. They had freedom to structure their reports as they wished.

The overall aim of the research was to explore the relationship between students' reflective writing and their IL development, identifying any changes in students' information literacy capabilities demonstrated through their reflective writing. Firstly the students' writing was assessed using the Moon's model of assess their level of reflection. Then, to identify the students' IL development we mapped the students' reflective writing outputs onto the SEA-change model of reflection. This was done by considering the reflection processes in the model, analyzing the content of each piece of reflection writing submitted by the students for the assessment, and looking of evidence within that writing that mapped onto the stages of the model. This enabled us to see the progression the students had made in their IL development.

Furthermore we wanted to engage with the reflective process ourselves as Scholars of Teaching and Learning to determine whether this was a valuable assessment in terms of student learning, and to consider if reflective writing is an effective means of assessing information literacy development. Data revealed through the method outlined above has fed into our tutor reflections on the facilitation and design of the assignment and our reflections on the depth of the student learning in terms of IL.

\section{Results}

An analysis of the content of the students' reflections was carried out to identify evidence of each of the elements of the SEA-change model within each reflection. For example, the following statement from student $\mathrm{S} 1$ shows clear evidence of having learnt from the process of reflection based on evidence their experience whilst on the module:

- I have learnt about information sources I didn't know existed, which proved useful in researching businesses and markets. I wouldn't have without the business intelligence module. I will definitely be using these sources more in the future. S1 
Table 2: Student reflections mapped on to the SEA-change model of reflection to illustrate the reflective process and levels of reflection achieved by students in reflection to their information literacy development.

\begin{tabular}{|c|c|c|}
\hline $\begin{array}{l}\text { Phases of } \\
\text { reflection }\end{array}$ & $\begin{array}{l}\text { Reflective process with frequencies } \\
\text { and \% achievement }\end{array}$ & Examples from students reflections mapped against the model \\
\hline \multirow[t]{3}{*}{ S- SITUATION } & $\begin{array}{l}\text { S1 - Trigger and/or catalyst - } \\
\text { clearly defined and understood } \\
\mathbf{9 ( 1 0 0 \% )} \text { met this criteria }\end{array}$ & $\begin{array}{l}\text { NB The trigger for all students was the requirement to fulfil an } \\
\text { academic assignment.: } \\
\text { "This reflective writing piece is based on my information literacy and } \\
\text { how I obtained information that was required for my coursework for the } \\
\text { Business Intelligence module. And how I learnt from my experience, how } \\
\text { I would change things looking back and was given the chance to redo it } \\
\text { and how I would do it in the workplace in the future." S5 }\end{array}$ \\
\hline & $\begin{array}{l}\text { S2 - Context - Contextual } \\
\text { consideration fully considered } \\
\mathbf{9 ( 1 0 0 \% )} \text { met this criteria }\end{array}$ & $\begin{array}{l}\text { "It is necessary to recognise the information needs that our business } \\
\text { client set out for us. For this, as a group, we interviewed our client } \\
\text { [names] who are two newly qualified nutritionists who intend to set up } \\
\text { a nutritional advice company. We identified our client's needs by asking } \\
\text { them to state their intentions and for key areas that they wanted us to } \\
\text { identify. They gave us some keywords which we recorded and kept as } \\
\text { part of identifying their information needs. I fully understood what they } \\
\text { required; they wanted us to focus on the lower sector of the community } \\
\text { and mother and baby groups. Through the interview it was also } \\
\text { discovered that they wished us to look at the general nutrition market." } \\
\text { S4 }\end{array}$ \\
\hline & $\begin{array}{l}\text { S3 - Critical (analytical or deep) } \\
\text { reflection of multiple perspectives } \\
\mathbf{8}(\mathbf{8 9 \% )} \text { met this criteria }\end{array}$ & $\begin{array}{l}\text { "Looking back we recognised the information need of our clients via a } \\
\text { recorded interview in which they explained to us their information need } \\
\text { which we used. This way of recognising their information need is the } \\
\text { best possible way of doing it and saved time figuring it out myself." S5 }\end{array}$ \\
\hline \multirow[t]{2}{*}{ E- EVIDENCE } & $\begin{array}{l}\text { E1 -Assimilation of the evidence } \\
\text { from the past or present } \\
\mathbf{8}(\mathbf{8 9 \% )} \text { met this criteria }\end{array}$ & $\begin{array}{l}\text { "I had been able to compare information from news agencies, weather } \\
\text { agencies. I was able to learn the value of commanding a good } \\
\text { understanding in gathering business intelligence. I felt that the qualities } \\
\text { I had learnt from being a mature student and various previous } \\
\text { employment positions added significance to our group." S8 }\end{array}$ \\
\hline & $\begin{array}{l}\text { E2 - Learning, process based on } \\
\text { evidence, new knowledge or } \\
\text { understanding acquired } \\
\mathbf{7}(\mathbf{7 8 \% )} \text { met this criteria }\end{array}$ & $\begin{array}{l}\text { "I have learnt about information sources I didn't know existed, which } \\
\text { proved useful in researching businesses and markets. I wouldn't have } \\
\text { without the business intelligence module." S1 }\end{array}$ \\
\hline \multirow[t]{3}{*}{ A- ACTION } & $\begin{array}{l}\text { A1 - Need for action identified } \\
\text { based on above } \\
\mathbf{8}(\mathbf{8 9 \%}) \text { met this criteria }\end{array}$ & $\begin{array}{l}\text { "It would appear that I did not establish the correct sources for my } \\
\text { need." S3 }\end{array}$ \\
\hline & $\begin{array}{l}\text { A2 } \text {-What action or change is } \\
\text { needed? Future. } \\
\mathbf{7}(\mathbf{7 8 \% )} \text { met this criteria }\end{array}$ & $\begin{array}{l}\text { "I perhaps could have stored the information all together in a document } \\
\text { in an organised fashion. This would have saved having several files. I will } \\
\text { consider this method in future projects." } 1 \text { 1 }\end{array}$ \\
\hline & $\begin{array}{l}\text { A3 -Action or change in behaviour, } \\
\text { or the situation, } \\
\mathbf{5}(\mathbf{5 6 \% )} \text { met this criteria }\end{array}$ & $\begin{array}{l}\text { "In order to prevent this happening to me again I have found a software } \\
\text { called DROPBOX which gives me instant synchronising of my work and it } \\
\text { has been working really great." S2 }\end{array}$ \\
\hline
\end{tabular}

The majority of the student reflections were quite deeply reflective, showing some analysis and evidence of learning. From the frequencies and percentages, it can be seen that students sometimes failed to follow their reflections through as deeply as they might. This was true of the three main phases of the proposed reflective process (Situation, Evidence, Action) within the SEA-change model. As the phases progressed the number of students who showed evidence of deeper reflection decreased. The element that the students engaged with least was considering how they had actually changed their behaviour as a result of their learning. To some extent this may be because this exercise relates to a company context and the students will not get an opportunity to put their learning into practice until they get their first jobs in the workplace.

An analysis of each student's reflection on their IL development showed that five students had shown evidence of reflecting against each element of the SEA-change model. One student's writing of their IL development was extremely descriptive rather than deeply reflective, and showed little evidence of learning (Table 3).

Table 3. The shaded cells show where the student has shown evidence of reflection against each element of the SEA-change model, and mapped against Moon's (2007) levels of reflection as an assessment tool. 


\begin{tabular}{|l|l|l|l|l|l|l|l|l|l|}
\hline Stage & Student 1 & Student 2 & Student 3 & Student 4 & Student 5 & Student 6 & Student 7 & Student 8 & Student 9 \\
\hline $\begin{array}{l}\text { Situation } \\
1\end{array}$ & Level 2 & Level 2 & Level 2 & Level 2 & Level 2 & Level 2 & Level 2 & Level 2 & Level 2 \\
\hline $\begin{array}{l}\text { Situation } \\
2\end{array}$ & Level 3 & Level 3 & Level 3 & Level 3 & Level 3 & Level 3 & Level 3 & Level 3 & Level 3 \\
\hline $\begin{array}{l}\text { Situation } \\
3\end{array}$ & Level 4 & Level 4 & Level 4 & Level 4 & Level 4 & Level 4 & Level 4 & Level 4 & Level 1 \\
\hline $\begin{array}{l}\text { Evidence } \\
1\end{array}$ & Level 2 & Level 2 & Level 2 & Level 2 & Level 2 & Level 2 & Level 2 & Level 2 & Level 1 \\
\hline $\begin{array}{l}\text { Evidence } \\
2\end{array}$ & Level 3 & Level 3 & Level 3 & Level 3 & Level 3 & Level 3 & Level 3 & Level 3 & Level 1 \\
\hline Action 1 & Level 2 & Level 2 & Level 2 & Level 2 & Level 2 & Level 2 & Level 1 & Level 2 & Level 2 \\
\hline Action 2 & Level 3 & Level 3 & Level 3 & Level 3 & Level 3 & Level 3 & Level 1 & Level 3 & Level 1 \\
\hline Action 3 & Level 4 & Level 4 & Level 1 & Level 4 & Level 4 & Level 1 & Level 1 & Level 4 & Level 1 \\
\hline
\end{tabular}

Table 4 gives an example of analytical reflective writing using Moon's (2007) levels of reflective writing. The example can be seen to reach Level 4 with clear evidence of deep analytical reflection on the student's IL development. The writing includes evidence of the consideration of others, (the business and the student group) with learning having taken place based on experience and evidence, with a need for change identified. This reflection illustrates the stages and elements of the SEA-change model of reflection in the context of information literacy development.

Table 4. An example of deep reflective writing mapped onto the SEA-change model of reflection.

\begin{tabular}{l}
\hline Process phases \\
\hline SITUATION \\
Trigger - academic assignment. \\
Context - business intelligence \\
assignment identified. \\
Multiple perspectives acknowledged \\
with some consideration of others \\
involved, the business need, though \\
this could be developed.
\end{tabular}

Evidence of self-questioning and critical analysis regarding the student's information needs and unfamiliarity with the topic and the task.

\section{EVIDENCE}

Evidence assimilated through listening in the initial interview, but also from the research process itself. Evidence to support the reflection is drawn from experience, and from consulting other group members.

Learning has taken place as a result of the experience, reflection on the exercise, and self-questioning.

The need for improvement is identified and a need for a change in actions when searching.

\section{ACTION}

The change action needed in the future has been identified, though the opportunity has not yet arisen for that change to happen.
An example of analytical reflective writing

"I believe that recognising the need for information is one of the hardest aspects of searching for information. If I don't fully understand what the topic is or what I am looking for then I am unable to effectively identify an information need. When searching for information for the businesses intelligence group work I was faced with a challenge. Despite the fact that the overall information need was presented by the company, the needs presented involved areas that were unfamiliar to me." S3

"To begin with my strategy would just involve a basic Google search and in the process I found myself gathering the information solely from company websites; however I knew deep down that more sources would be needed. It would appear that I did not establish the correct sources for my need. I began to feel the pressure because the inability of me to find good quality information would have a direct effect on the overall quality of work I produced and therefore the group. I eventually changed my search strategy and began to search MINTEL after a fellow group member shared their success of using it with me. I used companies and key words established through my initial search on Google. This proved to be successful as I was then able to find more, relevant information. Looking back on how I approached this task I can see where I was at fault. I can now see that Google is not always the most effective search tool. Instead, I should have taken a step back and considered the options and tools that were available to me; this would have removed the tunnel vision scenario which I brought upon myself. I also should have perhaps constructed more complex searches that used phrases and other specialised commands. It is evident that my search strategy formulisation needs improving. I also learned that I need to be more open minded when constructing search strategies and carrying out searches." S3

"I went straight to Google without devising an appropriate search strategy and as a result I found it hard to find a good amount of relevant information. At this time it did not occur to me to use MINTEL or any other business sources. On reflection this was perhaps the biggest flaw in my strategy as I didn't consider what sources would be best for my specific need. Also, looking back I should have emailed the clients for more information regarding their information needs as this would have most likely provided me with a more solid starting point and this would have saved me a great amount of time. When similar circumstances occur in the future I now know that if I have any further queries or reservations I should follow up on them." S3 
Overall there was a good level of reflection across all the writing. The students not only described the processes they went through in answering the business queries in IL terms, they also were critical of their actions, often analysing where they has gone wrong, and where they had done well, and considering this in the wider academic and business context.

\section{Discussion}

We have presented the $S E A$-change model of reflection illustrating change through the information literacy practice and development of the students. This model will now be discussed in relation to other teaching and learning concepts, tutor support in the reflective process, and information literacy development.

Looking at Table 3 and the students' reflections overall across the SEA-change model, the students reflected deeply about the context for their business intelligence assignment (examples in Table 2 and Table 4). They reflected on their searching of information sources to answer the business problem, and their use of resources:

- I couldn't find the exact information I needed for market trends as Mintel didn't supply specific nutrition market trends, but I used as much related information as possible. I'm pleased with this because it was still relevant information. S1.

They reflected on their learning in this process

- I have learnt that accessing business information can be hugely beneficial for other businesses and also expensive, reflecting its importance. $S 1$.

Most of the students identified areas where they needed to change what they did as a result of this learning

- On reflection, I feel I could have put more effort into searching for more reputable sources such as .edu but although finding some, I didn't find many. I need to focus on this as a weakness in order to improve. S1.

A number of the students, $56 \%$, were able to see how what they had learnt might be useful for their future:

- On reflection, I think I did well as I felt confident in selecting the best sources and with only one experience of difficulty, I found all the information I required using those sources. I have learnt about information sources I didn't know existed, which proved useful in researching businesses and markets. I wouldn't have without the business intelligence module. I will definitely be using these sources more in the future. S1

It is acknowledged that there are many variables in the reflective learning process (Mezirow, 1990). Each situation will be different, even for the same individual, each learning experience can be different, e.g. different tutors, different leaning groups, prior knowledge, available resources (Boud \& Walker, 1998; Hatton \& Smith, 1998). These variables need to be taken into account in the reflective process, hence the importance in deeper reflection, of understanding the context, and taking into consideration multiple perspectives (Boud \& Walker, 1998). The capabilities of each individual will be different, they may not have levels of criticality, or the motivation that allows them to engage deeply so will engage only at a surface level. This is where having the support of a reflective model such as the SEA-change model can be helpful to support students in the process, alongside the support of tutors or mentors. In this Business Intelligence assignment the students had the support throughout of the tutors, and their 
business partners as mentors. The students did not always use this support and sometimes commented on that fact:

- Also, looking back I should have emailed the clients for more information regarding their information needs as this would have most likely provided me with a more solid starting point and this would have saved me a great amount of time. S3

Tutors and mentors can help by ensuring that adequate support (or scaffolding) is in place to allow that truly deeply engaged critical reflection to take place, providing a sounding board throughout the exercise. This need for support and guidance is further confirmed in the literature; Mann, Gordon and MacLeod (2009) carried out a systematic review of 29 studies and found that guidance and supervision are keys to reflection.

The students in this exercise started out lacking in confidence with their IL skills and the ability to find the right information for the business partner/client. The students at this stage could be termed as dependent learners (Ford, 2008).

- I believe that recognising the need for information is one of the hardest aspects of searching for information. If I don't fully understand what the topic is or what I am looking for then I am unable to effectively identify an information need. When searching for information for the businesses intelligence group work I was faced with a challenge. Despite the fact that the overall information need was presented by the company, the needs presented involved areas that were unfamiliar to me. S3

Dependence refers to a learning situation where information is used directly by the student to inform the problem, the solution, and/or the reasoned evidence supporting the solution. The goal is to increase student confidence and autonomy so that they reach a learning situation in which the student finds information, and/or processes information to autonomously generate knowledge of what is the problem, the solution, and/or the reasoned evidence supporting the solution (Clifford, 1999). The students were successful in addressing in each case a very real business problem set by the business partners. All but one student showed clear evidence of learning from the exercise, and increased their confidence and learning autonomy:

- I wouldn't have known how to present business information in the format of a report unless the guidance and support was there. This taught me that I needed to use concise, summarized writing styles with all evidence based information in the appendix. I found synthesising the separately written information difficult to merge together as each individual has a slightly different writing style. I managed to overcome this by reading through the report several times, making amendments where necessary in order for the report to flow in a clear and understandable manner. I feel this was successfully achieved, although with more time and a larger word count, perhaps I could have added more value to the report. Overall, I am confident that we have conducted a well processed project and have indeed added value to our business client in both the report and the presentation. I hope they agree with this. S1

As students build their confidence and skills, they move to the state of autonomous learners and develop the ability to experiment with different approaches (Ford, 2008; Simons \& Klein, 2007).

Student 6 describes the process, firstly using tutor support by referring to lectures, and using mentor support from other group members, experimenting with different approaches to information seeking, and growing in confidence as the student is successful in finding appropriate resources for the task. 
- From lectures and discussions with the group we decided the best way to find relevant information was to first implement searches over the Internet to create a basic understand of the fulfillment for the information need. When these searches were finished we looked at the data and information we collected and then decided to use a more detailed approach, to successfully find more in-depth information for the business, as our first locational research was more of a preliminary experimentation of achieving specific results. S6

The reflective process is critical to embedding the learning process with students reflecting on their actions past and present and taking that learning forward. The need to develop the students' reflective capabilities can be overlooked. The importance that the tutor or mentor can have in that situation can be overlooked (Boud \& Walker, 1998; Barnett, 2005). Figure 1 shows possible relationships between reflection, learning, and tutor support showing a pedagogical approach with de-scaffolding as the student moves from being dependent to being increasingly autonomous (Lajoie, 2005). This paper has enabled us to illustrate this in the context of information literacy encapsulated in the following statement by student 7 .

- To conclude, I believe I have been aware of information literacy throughout my course nonetheless, carrying out this reflective report has enabled me to further deepen my understanding. It has helped me understand the competencies and reflect on how I can become more information literate in future. S7

Tables 2 and 4 illustrate the processes that the student's go through in this groups Business Intelligence exercise alongside the SEA-change model of reflection. The reflective writing model gives the students a vehicle for describing, reflecting on, analysing, and cementing their learning. Through the writing it can be seen that the students are thinking deeply about their experiences, what they have learned, how they need to or may change their behaviours, and how they might be useful for them in the future. The student's themselves are seeing the relationship and value of reflection in deepening their understanding of what they have learnt. As tutors we are able to reflect ourselves not just of the module feedback, but on the written student's reflection and this gives us further valuable insight into how we can better support the students and improve our teaching. Whitworth (2012, p. 50) comments on the "transformational power" that educators have in supporting students to learn and reflecting ourselves on learning techniques is an important aspect of our own development. The SEA-change model has provided a useful framework for supporting both staff and students in this assessment. It has enabled a structured approach to dealing with the complexity of information. (Jacobs \& Berg, 2011), and has been useful in highlighting the student learning, problem solving and critical reflective thinking (Oakleaf, 2008).

\section{Conclusions}

We have presented the SEA-change model of reflection, and we have considered this model in relation to information literacy and pedagogical approaches to learning and teaching support. All these models have been developed from the extent literature, experience in engaging with reflective practice, and an analysis of students reflections over a number of years.

The model illustrates the importance of situation, or context in the reflective process. The reflection draws on evidence often from experience and/or other research, from which learning takes place and culminates in the identification of the need for change, and often in actual change. The model shows that there are different levels of reflection. The examples of reflective writing taken from the Business Intelligence module illustrate these levels.

A scaffolding and de-scaffolding approach can be taken by tutors and mentees to support student learning and development through the reflective process. 
Understanding the reflective process and how to support deep reflection is important in understanding the value of reflection in academic learning within this information literacy context. The depth of reflections regarding their information literacy development demonstrated by these students, and our ability as tutors to map this development using the SEA-change model, leads us to conclude that this reflective assignment is a suitable means of assessing information literacy development.

This paper is based on a very small number of students; however, it forms part of a body of research carried out over a number of years at the Information School at Sheffield that has a reputation for its work in both information literacy and reflective practice. The development of reflective practice is increasingly present in the library domain in academic study, professional development, staff appraisal, and professional practice. Understanding the reflective process and how to support those engaged in reflective practice and encouraging students to become reflective practitioners is an important contribution that we can make. 


\section{References}

ACRL. (2000). Information Literacy Competency Standards for Higher Education. Chicago: Association of College and Research Libraries. Retrieved from http://www.ala.org/acrl/standards/informationliteracycompetency

ANZIIL. (2004). Australian and New Zealand Information Literacy Framework: principles, standards and practice. 2nd edition. Adelaide: Australian and New Zealand Institute for Information Literacy. Retrieved from http://www.library.unisa.edu.au/learn/infolit/Infolit-2nd-edition.pdf

Barnett, B. G. (2005). Developing reflection and expertise. Can mentors make a difference? Journal of Educational Administration(33)5, 45-59.

Bengtsson, J. (1995) What is reflection? On reflection in the teaching profession and teacher education. Teachers and Teaching: Theory and practice(1)1, 23-32.

Black, P.\& Plowright, D. (2010). A multi-dimensional model of reflective learning for professional development. Reflective Practice(11)2, 245-258.

Bordonaro, K. \& Richardson, G. (2004). Scaffolding and reflection in course-integrated library instruction. The Journal of Academic Librarianship 30(5), 391-401.

Boud, D., Keogh, R \& Walker, D. (1985). Reflection: Turning experience into learning. Abingdon: Routledge.

Boud, D. \& Walker, D. (1998). Promoting reflection in professional courses. The challenge of context. Studies in Higher Education(23),2, 192-206.

Bruce, C. \& Hughes, H. (2010). Informed learning: a pedagogical construct attending simultaneously to information use and learning. Library and Information Science Research(32)4, A2-A8.

CILIP. (2004). Information Literacy definition. Retrived from http://www.cilip.org.uk/getinvolved/advocacy/information-literacy/pages/definition.aspx

Clifford, V.A. (1999). The development of autonomous learners in a university setting. Higher Education Research and Development(18)10, 115-128.

Diekema, A., Holliday, W. \& Leary, H. (2011). Re-framing information literacy: problem-based learning as informed learning. Library and Information Science Research(33)4, 261-268.

Fallon, H. \& Breen, E. (2005). Developing information literacy skills to support project and problem-based learning. In T. Barrett, I. Mac Labhrainn \& H. Fallon (Eds.), Handbook of Enquiry and Problembased Learning: Irish Case Studies and International Perspectives (pp. 179-188). Retrieved from http://eprints.nuim.ie/539/

Ford, N. (2008). Educational informatics. Annual Review of Information Science and Technology(42)1, 497-544.

Ghaye, T. (2005). Developing the reflective healthcare team. Oxford: Blackwell Publishing.

Gilstrap, D.L. \& Dupree, J. (2008). Assessing Learning, Critical Reflection, and Quality Educational Outcomes: The Critical Incident Questionnaire. College \& Research Libraies(69)5, 407-426

Hatton, N. \& Smith, D. (1998). Reflection in teacher education - towards definition and implementation. Teaching and Teacher Education(11)1, 33-49. 
Hepworth, M. \& Walton, G. (2009). Teaching information literacy for inquiry-based learning. Oxford : Chandos

Hoffman, D. \& LaBonte, K. (2012). Meeting information literacy outcomes: partnering with faculty to create effective information literacy assessment. Journal of information literacy(6)2, 70-85.

Jacobs, H. \& Berg, S. (2011). Reconnecting Information Literacy Policy with the Core Values of Librarianship. Library Trends(60)2, 383-394.

Johnston, B. \& Webber, S. (2003) Information literacy in higher education: a review and case study. Studies in Higher Education(28)3, 335-352.

Kinikin, J. \& Hench, K. (2012). Poster presentations as an assessment tool in a third/college-level Information Literacy course: an effective method of measuring student understanding of library research skills. Journal of Information Literacy(6)2,86-96.

Koufogiannakis, D. (2010). Thoughts on reflection. Evidence Based Library and Information Practice(5)2, 1-3.

Lajoie, S. (2005). Extending the scaffolding metaphor. Instructional Science(33)5-6, 541-557.

Larrivee, B. (2000). Transforming Teaching Practice: becoming the critically reflective teacher. Reflective Practice(1)3, 293-307.

Lehlafi, A., Rushton, D. \& Stretton, E. (2012). Active and reflective learning initiatives to improve web searching skills of business students. Journal of information literacy (6)1, 35-49.

Lym, B., Grossman, H., Yannotta, L. \& Talih, M. (2010). Assessing the assessment: how institutions administered, interpreted, and used SAILS. Reference Services Review(38)1, 168-186.

Mann, K., Gordon, J. \& MacLeod, A. (2009). Reflection and reflective practice in health professions education: a systematic review. Advanced Health Sciences Education. Theory Practice(14)4, 595-621.

McGuinness, C. \& Brien, M. (2007). Using reflective journals to assess the research process. Reference Services Review(35)1, 21-40.

McKinney, P. \& Sen, B. (2012). Reflection for learning: understanding the value of reflective writing for information literacy development. Journal of Information Literacy(6)2, 110129.

Mery, Y. Newby, J. \& Peng, K. (2011). Assessing the reliability of locally developed information literacy test items. Reference Services Review(39)1, 98-122.

Mezirow, J. (1990). Fostering critical reflection in adulthood: A guide to transformative and emancipatory learning. San Francisco: Jossey-Bass.

Mezirow, J. (2006). An overview of transformative learning. In P. Sutherland \& J. Crowther (Eds.), Lifelong learning (pp. 24-38). London: Routledge.

Moon, J. (2004). A Handbook of Reflective and Experiential Learning: Theory and Practice. Abingdon: Routledge.

Moon, J. (2005). Guide for Busy Academics No. 4 Learning through reflection. Exeter: Higher Education Academy. 
Moon, J. (2007). Getting the measure of reflection: Considering matters of definition and depth. Journal of Radiotherapy in Practice(6)4, 191-200.

Mulherrin, E. (2009). The evolution of a testing tool for measuring undergraduate information literacy skills in the online environment. Communications in Information Literacy(3)2, 204-214.

Oakleaf, M. (2008). Dangers and opportunities: A conceptual map of information literacy assessment approaches. Portal: Libraries and the academy(8)3, 233-253.

Ondrusek, A., Dent, V., Bonadie-Joseph, I. \& Williams, C. (2005). A longitudinal study of the development and evaluation of an information literacy test. Reference Services Review(33)4, 388-417.

Secker, J. \& Coonan, E. (2011). A New Curriculum for Information Literacy. Retrieved from http://dspace.jorum.ac.uk/xmlui/handle/10949/16378

Sen, B. \& Ford, N. (2009). Developing reflective practice in LIS education: The SEA-change model of reflection. Education for Information(27)4, 181-195.

Sharma, S. (2007). From Chaos to Clarity: Using the Research Portfolio to Teach and Assess Information Literacy Skills. The Journal of Academic Librarianship(33)1, 127-135.

Simons, K. D. \& Klein, D. J. (2007). The impact of scaffolding and student achievement levels in a problem-based learning environment. Instructional Science(35), 1, 41-72.

Sonley, V., Turner, D. Myer, S. \& Cotton, Y. (2007). Information literacy assessment by portfolio: a case study. Reference Services Review(35)1, 41-70.

Walsh, A. (2009). Information literacy assessment: where do we start? Journal of Librarianship and Information Science(41)1, 19-28 .

Wheeler, D. Vellardita, L. \& Kindschi, A. (2010). Providing a credit information literacy course for an Engineering School. In C. V. Hollister (Ed.) Best practices for credit-bearing information literacy courses, (pp. 109-125). Chicago: Association of College and Research Libraries.

Whitworth, A. (2012) The reflective information literacy educator. Nordic Journal of Information Literacy in Higher Education(4)1, 38-55. 